\title{
MOHAMED BOUISSEF REKAB Y LA LITERATURA MARROQUÍ EN ESPAÑOL
}

\author{
Beatriz Mangada Cañas \\ Universidad Autónoma de Madrid
}

\begin{abstract}
RESUMEN: En el ámbito del hispanismo literario, la literatura marroquí en español aparece hoy en día como un corpus aún poco conocido por el lectorado hispanohablante. Frente al reconocimiento y la difusión de las variantes literarias en francés o en árabe, los autores marroquíes que han elegido y eligen libremente el español como lengua de creación artística recuerdan que la presencia española en Marruecos favoreció el nacimiento y florecimiento de una tradición literaria que cuenta con figuras relevantes como la de Mohamed Bouissef Rekab. Con el análisis propuesto de sus cuatro primeras producciones literarias se pretende ofrecer un nuevo acercamiento crítico a una de las variantes literarias menos estudiadas de las letras hispánicas.
\end{abstract}

PALABRAS CLAVES: Mohamed Bouissef Rekab, Marruecos, literatura, hispanismo, estudio filológico, español.

\section{MOHAMED BOUISSEF REKAB ET LA LITTÉRATURE MAROCAINE EN ESPAGNOL}

\begin{abstract}
RÉSUMÉ: Dans le domaine de l'hispanisme littéraire, la littérature marocaine d'expression espagnole demeure encore un corpus peu connu de la part du lectorat hispanophone. Face à la reconnaissance et la diffusion des variantes littéraires en français ou en arabe, les auteurs marocains qui ont choisi et choisissent librement l'espagnol en tant que langue de création artistique rappellent la présence espagnole au Maroc ainsi que la naissance et le fleurissement d'une tradition littéraire qui compte avec des figures emblématiques comme celles de Mohamed Bouissef Rekab. L'analyse proposée de ses quatre premières productions littéraires a pour objectif de fournir une nouvelle approche critique d'une des variantes littéraires les moins étudiées des lettres hispaniques.
\end{abstract}

MOTS CLÉS: Mohamed Bouissef Rekab, Marroc, littérature, hispanisme, étude philologique, espagnol. 


\section{La literatura marroquí en español}

Parte inherente de la cultura mediterránea, la literatura marroquí da prueba, a través de sus diferentes variantes lingüísticas, en lengua árabe, en lengua francesa y en lengua española, de su rico pasado histórico y de su privilegiada situación geográfica de apertura y de encuentro con otras culturas. A ellas se refería Mohamed Bouissef Rekab en un artículo sobre los primeros escritores marroquíes en lengua española publicado en 2005 por el Centro Virtual Cervantes:

La literatura marroquí de expresión árabe o francesa ha conocido vicisitudes diferentes a la de expresión española: la expresada en árabe, secular, ha conocido dos etapas: la precolonial (de fuerte influencia árabo-orientalista) y lo poscolonial; ésta última se somete a dos fuerzas: respetar la sacralidad de la lengua árabe o dejarse llevar por las modas literarias occidentales. En cuanto a la expresada en francés, de herencia colonial, conoce el paso de una generación a otra. La primera generación expresa lo exótico, según la visión colonialista. La segunda es más libre: los escritores eligen un camino más progresista de tendencia izquierdista. En cuanto a la literatura marroquí expresada en castellano, está luchando por abrirse camino en el panorama literario nacional y adquirir legitimidad como una forma más de la pluralidad de Marruecos (Rekab, 2005).

Es, pues, este contexto plurilingüe e intercultural, característico por otra parte de numerosos pueblos mediterráneos, el que permite entender el surgimiento y florecimiento de la literatura marroquí en español. Los hispanistas Mohamed Chakor y Sergio Macías proponen en su trabajo de 1996 unos hitos cronológicos, correspondientes a tres etapas en las que enmarcar las figuras más relevantes del hispanismo literario en Marruecos que arranca tímidamente a finales del siglo XIX con la figura pionera de Lahsen Mennum, autor de una crónica redactada en castellano en 1877 sobre la visita de una representación diplomática a Fez y que aparecerá publicada en el diario madrileño El imparcial. Al margen de este primer testimonio aislado, será en los años 1940-1950, al final del Protectorado español, cuando vea la luz un primer corpus de escritores marroquíes que elegirán el español como lengua de expresión artística. A esta generación de fundadores pertenecen entre otros, Mohamed Chakor (1937), reconocido periodista, hispanista y autor de más de treinta obras, algunas de las cuales han sido galardonadas; así como Mohamed Temsamani (1920), intelectual marroquí que participará de la vida cultural en la zona española y que continuará expresándose en español después de la independencia de Marruecos. En estos primeros años, la revista actúa como principal medio de edición (Lomas, 2011: 69). A partir de los años 1970, comienza a forjarse una segunda generación que contará con el apoyo institucional que supondrá el interés 
universitario surgido en estos años por difundir el hispanismo marroquí. Sobresale la figura de Simon Levy (1934-2011), autor del gran trabajo lingüístico La lengua diaria marroquí, reflejo de unas relaciones seculares entre España y Marruecos que contribuirá a consolidar la formación de numerosos hispanistas marroquíes; durante estos años, nuestro autor objeto de estudio publica sus primeros poemas. Una tercera etapa de consolidación y más rica en sus producciones arranca en los años 1990. Destacan figuras como el poeta Abderrahman El Fathi (1964), el escritor Ahmed Daoudi (1959) o autores ya conocidos como Mohamed Chakor o Mohamed Bouissef Rekab (1948) quienes consolidan su trayectoria literaria a lo largo de esta etapa. Sin embargo, y a pesar de esta creciente constelación de nombres, Juan Goytosolo se sorprende del número tan reducido de españoles conocedores de esta tradición literaria (Chakor y Macías, 1996: 287). Por su parte, Eloy Santos repara en la tradicional indiferencia española con respecto al mundo árabe alegando raíces históricas "qui se plongent dans le labyrinthe historique de la période improprement appelée Reconquête, et dont les ramifications envahissent aujourd'hui encore de vastes espaces de la mentalité commune". Y atribuye la falta de difusión de esta tendencia creadora a una infraestructura editorial insuficiente y esporádica (Santos, 2006a).

En la misma línea se sitúa la reflexión de Alfonso de la Serna en torno al número desproporcionado de hispanohablantes en Marruecos -2 millones- frente a una comunidad francófona marroquí que contaba con 5 millones de hablantes a finales de los años 1990 (Chakor y Macía, 1996: 5). El apoyo e interés institucional parecen explicar el reconocimiento de los escritores francófonos marroquíes, tales como Tahar Ben Jelloun o Driss Chraïbi, mientras que los compatriotas que optaron por el español apelando a lejanas raíces históricas compartidas y generadoras de una particular simbiosis lingüística y cultural entre el español y el árabe, continúan reclamando su derecho al reconocimiento. Sin embargo, para Alfonso de la Serna son precisamente estas relaciones, al margen de todo exotismo, sino más bien fruto de políticas educativas y culturales de los dos Protectorados, las que permiten que: "Al preservar su identidad y especificidad, los escritores marroquíes en lengua española y francesa consideran que no están expuestos a la aculturación, como argumentan algunos críticos, y que su misión, como portadores de valores multiculturales, es enriquecer y fomentar el diálogo de culturas en el mundo" (Chakor y Macías, 1996: 12).

En el plano académico y crítico, la celebración en noviembre de 1994 en Fez del primer coloquio internacional sobre escritura marroquí en lengua española permite tomar conciencia de manera formal del estado de esta reciente tendencia ar- 
tística. Las actas de este encuentro fueron publicadas en 1998 y aseguraron la transmisión del pensamiento crítico de los principales investigadores en este ámbito, al mismo tiempo que supusieron el descubrimiento de una realidad literaria, sin duda, incipiente, pero susceptible de interesar a los especialistas tanto del Magreb como a la comunidad de hispanistas ${ }^{1}$.

Seis años más tarde tendrá lugar un segundo encuentro sobre el mismo tema, aunque en esta ocasión el análisis y el debate se centrarán en la amplitud y el interés de las obras de los principales autores marroquíes de expresión española. Especialmente reseñable resulta la contribución de Ahmed El Gamoun quien pone de manifiesto la contradicción que se dará en las diversas antologías publicadas durante la década de 1990 cuyos títulos portarán referencias explícitas al concepto de literatura, al tiempo que los autores seleccionados pertenecerán a ámbitos que exceden la literatura, como la historia, la traducción, el periodismo y otros. Este hecho podría evitarse, según El Gamoun, empleando una designación más prudente como "joven tradición de escritura marroquí en lengua española" (Tazi, 2004: 156). Para Jean-Marc Moura, la aparición de estas antologías -fenómeno que también se dio en los inicios de las literaturas francófonas postcoloniales- revela la existencia de un apoyo académico, institucional y editorial, por otra parte necesario para una tradición textual que contará de este modo con un sustento teórico y crítico (Moura, 2009: 117). De este modo, la literatura hispano-marroquí afianza su trayectoria y encuentra condiciones más favorables para su tímida difusión. Su estudio debe considerar en todo momento la dimensión plurilingüe que presidió su aparición; circunstancia a la que El Gamoun se refiere en los siguientes términos: "Entonces, escribir en una lengua extranjera en Marruecos, con la que nos unen lazos históricos y que sigue marcando nuestra actividad cotidiana, no puede ser más que la expresión de una faceta de este Marruecos plural” (El Gamoun, 2004: 153). Pensamiento éste que nos lleva a recordar el de Khatibi quien en Maghreb pluriel subrayaba que "le bilinguisme et le plurilinguisme ne sont pas dans ces régions -Al Mareb- des faits récents. Le paysage linguistique maghrébin est encore plurilingue: diglosie

1. Los autores de Calle del Agua, Antología contemporánea de Literatura Hispanomagrebí recuerdan que "No obstante hay que señalar que el fenómeno de una literatura española escrita en el Magreb se centra mayoritariamente en Marruecos, debido a su más amplio recorrido histórico y a su ya abundante oferta literaria. Por su lado, en Túnez, encontramos, por el momento, a destacados hispanistas y a una incipiente producción literaria de alto nivel. En Argelia existen interesantes movimientos en torno a las universidades de Argel y Orán que además de haber aportado importantes estudios hispánicos, podrían desembocar en una próxima producción de creación literaria" (Gahete, Limani, Mgara, Sarria y Tazi, 2008: 21). 
(entre l'arabe et le dialectal, le berbère, le français, l'espagnol au nord et au sud du Maroc)" (Khatibi, 1983: 179). Y es justamente esta condición plurilingüe y multicultural la que permite a los escritores marroquíes optar libremente por el español como lengua de escritura convirtiéndose de este modo en "passeurs d'une culture à l'autre" (Madarhri, 1991: 17). Sirva de ejemplo ilustrador del interés de esta tradición literaria marroquí en español el acercamiento crítico propuesto a las cuatro primeras producciones literarias de Mohamed Bouissef Rekab, una de las figuras más significativas del hispanismo literario en Marruecos.

\section{Mohamed Bouissef Rekab, escritor marroquí de expresión española}

Mohamed Bouissef Rekab nace en 1948 en Tetuán. De padre marroquí y de madre española, Rekab cursa estudios universitarios en la universidad de Rabat y posteriormente en la Universidad Autónoma de Madrid, donde se doctora en 1983. Su carrera como profesor de español se inicia en la educación secundaria y prosigue en 1984 en la Universidad de Tetuán. Desde 2005 ejerce como profesor de la Universidad Nacional de Educación a Distancia en Ceuta. Su producción literaria arranca en 1994 con la publicación de un primer conjunto de relatos titulado El Vidente que sitúa al lector en el Marruecos de los años 80, ofreciendo un fresco muy representativo de la sociedad marroquí de aquellos años. En 1995 aparece Desmesura, el primer eslabón de una trilogía que cuenta con dos títulos más, Inquebrantables, publicado en 1996 e Intramuros de 1999; en esta ocasión, Rekab recurre a recuerdos de su infancia para transportar al lector hasta una pequeña aldea del norte del Rif donde discurre la acción; a través de los avatares de dos generaciones de personajes, nuestro autor repara en la oposición mundo rural/mundo urbano como proyección de la dicotomía tradición/modernidad propia de la sociedad marroquí de los años 70 .

Su trayectoria literaria cuenta con cinco títulos más; Los bien nacidos de 1998; El dédalo de Abdelkrim de 2002; El motín del silencio y La señora de 2006; y Aixa, el cielo de Pandora aparecida en 2007. En todas ellas Rekab escenifica el Marruecos contemporáneo con el fin de ofrecer diferentes aspectos de la sociedad marroquí actual. La escritura de M. Bouissef Rekab gira, pues, de manera iterativa en torno a la realidad marroquí que evoluciona lentamente al ritmo de la "disparition du monde paysan face à l'avancée de la culture urbaine, à la complexité de la condition de la femme, et ses tentatives pour surmonter la discrimination professionnelle et sexuelle", como muy bien señala el propio escritor (Santos, 2006a).

Asimismo es autor de una antología de escritores marroquíes de expresión española titulada Escritores marroquies de expresión española. El grupo de los 90, 
publicada en Tetuán en 1997; y de varios poemas que aparecieron en la revista Liga Árabe, bajo el título de Temas Árabes en diciembre de 1986.

A pesar de ser considerado como uno de los representantes más destacados de la tradición literaria hispano-marroquí, su figura y obra dan buena muestra de la falta de difusión del corpus al que pertenece y a la que el profesor El Gamoun se refería del siguiente modo: "Lo que caracteriza esta literatura es que representa un conjunto de experiencias esporádicas, que no han llegado todavía a resaltar del panorama literario marroquí y adquirir, de este modo, su legitimidad como una nueva forma de expresión nacional" (El Gamoun, 2004: 158). A lo que E. Santos añade: "En ce qui concerne le contenu des œuvres, la première impression que certaine d'entre elles produisent sur le lecteur est celle d'une certaine étrangeté linguistique. En effet, certaines maladresses stylistiques et narratives ainsi que la perception d'une rudesse verbale sont révélatrices du fait que l'instrument-langue traverse encore un processus de maturation et d'affinement progressif pour rendre compte d'un projet esthétique" (Santos, 2006a).

2.1. El vidente. "El cuento es atrapar en el aire unos trozos de vida que pasan" (Rekab, 1994: 15)

En 1994, la Asociación de Actividades sociales y culturales de la Facultad de Letras de la Universidad de Abdelmalek Esaadi publica El Vidente, un conjunto de trece cuentos, de extensión homogénea, a excepción del primero y del penúltimo, más largos que el resto, y que cuentan la mayoría de ellos con un título evocador del contenido de los mismos. Desde un punto de vista de los actantes, los hombres y los niños, en su condición de protagonistas, dan buena muestra de la sociedad marroquí de la época. Los amores sinceros, pero en ocasiones imposibles, las infidelidades, el comercio de drogas, la pobreza y las esperanzas de los más desgraciados constituyen los principales ejes temáticos de esta primera obra analizada. Las referencias temporales permiten anclar los relatos en el Marruecos de los años 80, mientras que el contexto espacial ofrece una galería de lugares diversos, tales como interiores de hogares, de oficinas, salas de cine, el mercado como lugar de encuentros o el mar como abismo y puente entre oriente y occidente; una coordenada espacial que discurre paralela al hilo conductor del relato y que ofrece descripciones de los rincones y aspectos menos conocidos del país. Dentro de este panorama, España aparece como una tierra de ensueño y de utopías. Asimismo, encontramos numerosas referencias a las ciudades marroquíes, y de manera especial a la ciudad natal del autor, Tetuán, descubriendo al lector el lado más humilde y pre- 
cario de la sociedad marroquí con sus esperanzas, sus ilusiones y donde reinan la envidia, el robo, las indiferencias y el sufrimiento de los más débiles.

En ciertas ocasiones, el relato abandona el país natal de Rekab; es el caso del noveno cuento, titulado "Madre" que nos acerca a la dureza y a los horrores de la guerra del Líbano a través de la historia de una joven libanesa que pierde a su madre y cuyo dolor y tristeza arrastran a la joven hacia la desesperación y la sed de venganza. Este acontecimiento histórico reaparecerá como temática central de algunos de sus poemas más insignes.

Desde un punto de vista estilístico, la sintaxis del discurso literario de este primer texto creativo se caracteriza por frases cortas de gran sencillez en las que se entremezclan diálogos, descripciones y la acción del relato, dando viveza a la narración. Se trata de una escritura que ofrece una excelente muestra del valor testimonial de los inicios de una tradición literaria marroquí que recurre al español como lengua de creación artística, al mismo tiempo que recuerda con su testimonio la presencia arraigada del español en tierras norteafricanas, de manera especial en ciudades como Tetuán, que Francisco Corral define de este modo: “Tetuán es esencialmente una ciudad-nudo, una encrucijada de culturas por la que han circulado fenicios, romanos, púnicos, godos, árabes, portugueses, españoles... Tierra de límites junto al extremo norte de África y a un paso del Estrecho. Tierra, por tanto, de confluencias, de fortuna y de conflictos" (Rekab, 1994: 11).

Para su primera obra narrativa, Mohamed Bouissef Rekab elige el cuento por su capacidad de reunir en una misma forma literaria, lo real, lo irreal y lo fantástico, partiendo de elementos diversos como un sueño, un deseo o una fotografía; pero también por su fugacidad y la posibilidad que le otorga de atrapar "trozos de vida que pasan" (Rekab, 1994: 15). En este sentido, sus intenciones quedan claramente recogidas en la introducción de El Vidente:

Escribir cuentos en español es una de las asignaturas pendientes de los intelectuales marroquíes, que si lo han hecho de manera magistral en francés, no ha sido el caso de la lengua de Cervantes. Nuestro propósito es llenar ese hueco que hay y presentar al público una pequeña serie de cuentos en español que en cierta medida explican el actual estado de cosas en nuestro país. [... ] Hacerlo para que el Marruecos enigmático, el de los estereotipos, deje de ser una tierra secreta para los españoles y se convierta en una continuación del pensamiento del sur de Europa, de la misma manera que lo es su geografía, sin olvidar que en este país se mezcla la tendencia de Occidente con la de Oriente, ofreciendo un amplio abanico de posibilidades ideológicas (Rekab, 1994: 15). 
De este modo comienza nuestro autor objeto de estudio su trayectoria como escritor en lengua española; un español de resonancias franco-árabes que permiten entender la presencia en el texto de galicismos y el recurso habitual a la lengua árabe coloquial para referirse, entre otros, al concepto de extranjero o para introducir saludos e interjecciones que acercan la cultura marroquí al lector. El cuento titulado "El botín", el más largo de todos, es el que presenta un mayor número de frases, términos y expresiones en árabe, en cualquier caso, siempre acompañados de su correspondiente traducción al español. Esta dimensión pluri-lingüística e intercultural queda reforzada y enriquecida mediante la alusión intertextual al principio de cada capítulo a escritores hispanohablantes tales como César Vallejo, Federico García Lorca, Guillermo de la Torre o Julio Cortázar.

\subsection{Desmesura, primer eslabón de una trilogía telúrica}

Un año después de la aparición de El Vidente, Mohamed Bouissef Rekab publica su primera novela que titula Desmesura. En esta ocasión, nuestro autor centrará la narración en torno a la descripción de las esperanzas, las pasiones y los dramas de seis jóvenes, estructurando la misma en dos libros con un total de siete capítulos; de este modo, consigue establecer un paralelismo con las siete puertas de su ciudad natal, que vuelve a configurarse como topos recurrente de su universo ficcional. El hilo conductor del relato nos sitúa en esta ocasión en el Marruecos de finales de los años 60, y más concretamente en el verano de 1969. La referencia a la llegada del hombre a la Luna permite ubicar temporalmente una narración que cuenta con escasos elementos cronológicos concretos y que retoma una vez más la descripción del mundo rural en evolución decadente frente al atractivo de las grandes ciudades como temática de fondo. Para su primera novela nuestro escritor ahondará en aspectos tales como la pobreza, la creencia y el respeto ferviente de las reglas coránicas o el deseo por parte de los más ancianos de conservar las tradiciones ancestrales relacionadas con el matrimonio o el estilo de vida rural. Tres personajes masculinos, Sadek, Munem y Sel-lam y tres femeninos -Rachida, Nezha y Saadía - constituyen el doble triángulo amoroso que determinará el desenlace de la acción.

Representantes de las nuevas generaciones, los tres jóvenes mencionados luchan por escapar de las exigencias del mundo rural escondiendo a menudo sus humildes orígenes con el fin de prosperar en la ciudad de Tetuán, garante de las modernidades de las grandes urbes. A pesar de lo cual, esa imagen utópica no tardará en desvanecerse ante una realidad menos idílica. Frente a este éxodo de las jóvenes generaciones, Si Hmed, el padre de Nezha, simboliza con su carácter de 
trabajador innato un mundo rural que va apagándose poco a poco (Rekab, 1995: 41). En cuanto a la tríada femenina, ésta bascula entre la sumisión de la joven Nezha, de nobles sentimientos y los deseos de venganza de Rachida cuyos actos impulsivos le costaran la vida a su padre, presa de la deshonra. La tercera figura femenina, la prostituta Saadía se presenta como una mujer con decisión que no cesa en su empeño de abandonar su condición de mujer de todos con el fin de lograr una vida mejor.

El título del primero de los dos libros que componen la organización de Desmesura nos recuerda el peso de la superstición en la sociedad rural marroquí. En efecto, "Sequedades" arranca con una referencia a la mala cosecha que se espera en caso de que no llueva, lo que lleva a los habitantes del pequeño pueblo del Rif, Bani Maaden - que es también una de las tribus más importantes de la región de Tetuán- a organizar un acto colectivo de plegarias para lograr que llueva. De forma paralela a esta movilización popular el relato se detiene en describir el empeño de Sadek en alquilar un pequeño apartamento para seguir con sus encuentros clandestinos con Saadía, al mismo tiempo que mantiene su relación con Rachida. Esta doble vida amorosa, a la que se añadirá una tercer mujer, su prometida Nezha, estallará en el segundo libro titulado "La Verdad". Finalmente, gracias a la encuesta que lleva a cabo la Gendarmería para aclarar el suicidio del padre de Rachida, el lector comprende que el origen de este fatal desenlace es el hijo que espera Rachida, fruto de sus relaciones con Sadek, futuro marido de Nezha. En este juego de ocultaciones y revelaciones, el enfermero de la aldea desempeñará una figura clave de confidente de los aldeanos que se verá reforzado en las dos siguientes novelas que componen la trilogía.

Al igual que en El Vidente, Rekab recurre de nuevo a la intertextualidad en cada inicio de puerta o capítulo con una cita evocadora del contenido que espera al lector. La elección se lleva a cabo entre autores españoles y una referencia en francés a Tahar Ben Jelloun. Y es que la escritura de Mohamed Bouissef Rekab gusta de una sencillez enunciativa no desprovista de una dimensión plurilingüe que se manifiesta a través de la presencia recurrente de la lengua árabe. Ésta aflorará a lo largo de todo el texto diseminando la narración de términos y expresiones en relación con la religión, la alimentación y la vestimenta. El árabe clásico de los rezos y el árabe dialectal de los diálogos conviven en la novela y ejercen en estos primeros textos fundadores de la literatura marroquí de expresión española un poder connotativo que ofrece la ocasión al lector de acercarse a una dimensión más íntima de la sociedad marroquí. Si bien esta función fue detectada por Malika Embarek en un estudio que realizó sobre textos de Juan Goytosolo, como hemos visto, 
también encuentra una similitud funcional en la primera novela de Rekab (Chakor y Macías, 1996: 146-149).

\subsection{Inquebrantables o el amor como dimensión temática}

En 1996 aparece publicada la segunda novela de nuestro autor con la intención de dar continuidad a Desmesura. Una vez más, volvemos a encontrar una estructura narrativa edificada en torno a siete capítulos que se inician con una breve cita en francés o en español perteneciente a autores muy variados pero cuyo significado parece querer siempre actuar como epifanía del contenido que el lector está a punto de leer. La acción no cambia de escenario, de manera que seguimos en la pequeña aldea donde había transcurrido Desmesura, aunque en esta ocasión, Bani Maadán y sus habitantes son percibidos y descritos desde diferentes perspectivas según la instancia enunciativa, provocando en ocasiones duplicidades narrativas en torno a un mismo acontecimiento; es el caso, por ejemplo, de la narración de la sequía que se abate sobre la aldea y de las plegarias de súplica que le siguen (Rekab, 1996: 121); pero también de la muerte del padre de Rachida o de la boda de Nezha y Sellhan que cierra el primer relato (Rekab, 1996: 45). En lo que a la acción del relato se refiere, ésta girará en torno a Farid, el enfermero que comunicó a Rachida su embarazo en el primer libro. Este personaje y sus aventuras amorosas se convertirán en epicentro narrativo alrededor del cual se irán engarzando los relatos anafóricos de las vidas de los personajes que le rodean. La linealidad del relato se verá constantemente entrecortada por la inserción intermitente de extractos que reproducen los pensamientos de la madre de Farid y de la hermana de ésta, que quieren que sus dos hijos, Farid y Salma se casen juntos, al margen de los deseos particulares de estos últimos. El lector verá confirmada su impresión de que ciertas letanías recorren el texto con la incorporación al relato de los incisos mesiánicos y moralizantes de Siru, personaje misterioso y popular que adquirirá su verdadero significado en el tercer eslabón de la trilogía. Nos hallamos, pues, ante una diégesis sin duda compleja y objeto de una nueva fragmentación al final del relato con la aparición de un "yo" desconocido que intenta dar continuidad al relato.

La dicotomía espacial entre el medio rural y el atractivo de las ciudades que había caracterizado Desmesura pierde fuerza en este segundo volumen de la trilogía. Los personajes parecen aceptar su medio de vida y el contraste entre estos dos espacios ya no es vivido de manera tan antagónica, sino más bien como un movimiento de intercambio permanente, tal y como lo señalaba el propio Mohamed Bouissef Rekab (Tazi, 2004: 53). Tetuán, antigua capital del Protectorado sigue simbolizando la prosperidad ante los ojos de los habitantes del campo cuyo uni- 
verso se proyectará textualmente a través de discretas referencias a los interiores de hogares, a sus costumbres y a sus actividades cotidianas.

En lo que a la temporalidad se refiere, señalemos que Inquebrantables cuenta con una coordenada temporal bien construida en torno a referencias explícitas a los acontecimientos históricos que marcaron la historia reciente de Marruecos. Citemos, por ejemplo, la presencia en el texto de un largo pasaje en forma de crónicas que permite al autor evocar los días que precedieron la Independencia de 1956 e introducir una dimensión crítica, pero también simbólica de las dos figuras protectoras que constituyeron España y Francia (Rekab, 1996: 41-43). Por un lado, el lector encontrará numerosas alusiones, positivamente connotadas, a la presencia española en Marruecos, de manera notable a través de figuras como los amigos españoles, siempre benefactores o a las ayudas del gobierno español que logran transmitir la idea de una España culta, sinónimo de civilización. Y por otro, la referencia textual al exilio real impuesto por los franceses, así como la narración de Maimún de un incidente que vivió en Toulouse en el que los franceses lo trataron de ladrón sin ninguna prueba, anécdotas que introducen en el texto un sentimiento negativo hacia Francia, de traición hacia el pueblo marroquí (Rekab, 1996: 68-69).

Desde un punto de vista de los personajes, la novela se configura en torno a una bipolaridad hombres/mujeres que toma forma a través de la recreación ficcional de dos universos bien diferenciados. Por una parte, los hombres se muestran en sociedad con sus aspiraciones profesionales y personales, pero siempre agraciados con una inmunidad que permite explicar, por ejemplo, que Si Kaddur pueda ocultar su esterilidad, condenando indirectamente a sus dos mujeres a la desgracia y a la deshonra. Y por otra, las mujeres transitan con cierta libertad dentro de sus propios espacios, preferiblemente interiores de hogares, el mercado o los baños públicos. Las más jóvenes logran imponer su criterio en el ámbito del trabajo y en el de los sentimientos; aunque en numerosas ocasiones el relato deja entrever que son objeto habitual de críticas, como en el episodio del asesinato en la carretera en donde los comentarios masculinos ejercen un papel moralizador hacia la actitud demasiado frívola de Farid y de las jóvenes marroquíes en general (Rekab, 1996: 95-106).

En lo que a la textura lingüística se refiere, ésta adquiere matices interculturales mediante la aparición intermitente pero continua del árabe en forma de términos relacionados con el tratamiento social de los individuos ("jalti" (Rekab, 1996: 36), el universo de los baños públicos o la vestimenta - "gelsa", "bhu”, "tabbajat"-(Rekab, 1996: 150); aunque a diferencia del primer volumen, en esta oca- 
sión, éstos aparecen desprovistos de traducción, de manera que la lengua árabe dialectal se integra con elegancia dentro de frases sencillas. Por último y como ya ha sido señalado previamente, la presencia en el texto de extractos dialógicos en lengua francesa confirma la impresión negativa de la colonización francesa.

\subsection{Intramuros, o las consecuencias de amores ilegítimos}

Publicada en 1999, la tercera novela de la trilogía escrita por Mohamed Bouissef Rekab presenta una estructura diferente con respecto a los dos volúmenes precedentes. En esta ocasión, nos encontramos ante una simple segmentación que juega con la bipolaridad de dos libros con dos capítulos cada uno y con tan sólo dos elementos para-textuales, una cita de Octavio Paz y otra de Antonio Gala cuyo contenido temático anuncia el peso del amor y sus diferentes manifestaciones en el conjunto de las estructuras narrativas. Un prólogo y un epílogo permiten abrir y cerrar una narración que vuelve a tener como decorado espacial la pequeña aldea de Bani Maadán, al norte del Rif. Un nuevo personaje entra en escena; se trata de la instancia narrativa que se cuestionaba misteriosamente al final de Inquebrantables acerca de los rodeos y avatares del destino y que ahora actúa como narrador potencial de la historia que el lector tiene entre manos; a él se dirige otro narrador externo en forma de un "tú" que nos informará acerca de este nuevo personaje desconocido; se trata un abogado que se ha casado con Turia - joven amante de Farid, el enfermero en el segundo tomo de la trilogía - y que ahora visita a Siru, el "meydub" o agorero del pueblo, en el centro de tuberculosos de Ben Karrich para escuchar historias y secretos de los habitantes de este pequeño pueblo que no tardarán en convertirse en fuente de inspiración para su novela. Se produce entonces un juego enunciativo que enriquece y vuelve más compleja la dimensión diegética de Intramuros. El autor buscará incrementar ese efecto de confusión narrativa con la introducción en el relato de pasajes en cursiva que retoman el pensamiento de dos personajes; por un lado Kabir, el chofer de Si Kaddur, marido de Fatiha y amante de la segunda esposa de su patrón; y por otro, el de Fadila, la madre impotente y desesperada por el destino que aguarda a su hija Fadiha, mujer de Kabir. Recordemos que Rekab ya había recurrido a esta técnica en Inquebrantables con el fin de crear un efecto de polifonía enunciativa.

En lo que a la coordenada temporal se refiere, el acercamiento al tiempo histórico nos remite a la segunda mitad de los años 70 , gracias a las alusiones a la salud de Franco y a la proximidad de su muerte. En cuanto al tiempo interno del relato, detectamos desdoblamientos cronológicos entre el relato sobre los habitantes de Bani Maadán que transmite Siru a su visitante y lo que éste último personaje va 
descubriendo en sus sucesivas visitas a la aldea. Estos anacronismos, así los denominará él mismo, encuentran su origen en la naturaleza singular y misteriosa de todo lo que rodea Siru, alcanzando incluso su muerte y entierro (Rekab, 1999: 53). A pesar de lo cual, el valor profético de sus confesiones permiten al lector entrever que las relaciones prohibidas entre Kabir y Habiba son la causa de todos los males que se ciernen sobre la familiar de Si Kaddur (lo que explicará, por ejemplo, la ceguera pasajera de Munir, hijo ilegítimo de Habiba y Kabir y que Si Kaddur cree ser su propio hijo, en el capítulo dos del segundo libro; o los seis dedos, malformación genética que comparten Munir y Abdelhay y que el faqih atribuye a las mismas causas incestuosas). Mediante estos episodios Rekab logrará además focalizar la dimensión temática en el peso de la superstición en el medio rural marroquí.

La muerte inesperada de Siru cierra la primera parte de Intramuros dando paso a un segundo libro que comienza sin referencias temporales concretas. Tan sólo encontramos un comentario referido a los estudios de los nietos de Si Kaddur, ya adolescentes, como figuración del tiempo transcurrido. El relato prosigue, pues, a pesar de la muerte de Siru. Las conversaciones que el misterioso e incipiente novelista mantuvo con el agorero dan continuidad al relato. De esta manera, este personaje encarnado en el deíctico "yo" toma el relevo del "meydub" y asume su papel moralizante al dejar actuar el destino, aun conociendo el final que espera a los personajes de su historia.

El peso de la narración relega a un segundo plano una topografía ya conocida por el lector. Tan sólo destacaremos la mirada descriptiva del nuevo narrador a su llegada a la aldea que aporta una nueva perspectiva de Bani Maadán (Rekab, 1999: 37); al igual que el paseo de Si Kaddur por Tetuán, cuyo desplazamiento favorece el descubrimiento de aspectos menos agradables de la ensoñada ciudad (Rekab, 1999: 44). Otro elemento espacial recurrente lo hallamos en la imagen positiva de España que aflorará de nuevo a lo largo de toda la novela, de manera especial a través de referencias a edificios emblemáticos como el Consulado o la Biblioteca española o bien mediante alusiones indirectas que remiten al fútbol o a equipos españoles (Rekab, 1999: 63, 69, 71).

El episodio que narra el viaje a la Meca de algunos de los miembros de la familia de Si Kaddur (capítulo dos del segundo libro), así como las referencias a fiestas religiosas señaladas o los comentarios sobre el peso de los "faqihs" en las aldeas completan el crisol de facetas en que se manifiesta la cultura marroquí; una cosmogonía en transformación inevitable debido al éxodo urbano progresivo - a pesar de intentos como los de Munir, personaje que nos recuerda a Si Hmed en Desmesura - y que el autor de Intramuros ha querido acercar al lector hispanohablante. 
Y será precisamente en este espacio urbano tan atractivo para las nuevas generaciones donde aflore de manera más evidente la diversidad lingüística emblemática del pueblo marroquí. Lo que explica los incisos del narrador acerca del hecho que en numerosos comercios de Marruecos los comerciantes sigan hablando español, o que el francés haya quedado relegado al ámbito educativo, fruto del pasado colonial (Rekab, 1999: 106). Como en ocasiones anteriores, la latencia del árabe coloquial y del árabe clásico se filtra en los apelativos, en los rezos o en las referencias a términos relacionados con la vestimenta o con las fiestas. En esta ocasión, cómplice de un lector, probablemente monocultural, el autor de Intramuros propone la traducción de estos elementos interculturales con el fin de evitar posibles interferencias comunicativas.

La trilogía concluye con el relato retrospectivo que propone el nuevo enfermero que ha venido sustituir a Si Aziz, logrando de este modo recapitular ciertos elementos narrativos importantes para el desenlace de la historia; es el caso del incendio purificador en casa de Si Kaddur que permite que los dos culpables de tantos males crucen finalmente el puente, parafraseando las profecías de Siru: "El puente está para cruzarlo y que cuando se cruza, termina la misión terrena de los hombres" (Rekab, 1999: 140).

\section{Conclusiones}

Del acercamiento a la producción literaria de Mohamed Bouissef Rekab se desprende el interés de su contribución al patrimonio literario en lengua española, así como su aporte a la construcción de una memoria cultural e histórica, híbrida y compartida (Tazi, 2004: xi).

El estudio de sus cuatro primeros escritos nos ha develado la presencia en Rekab de la función comunicativa a la que se refería El Gamoun cuando reflexionaba sobre los textos fundadores de la incipiente tradición literaria marroquí en lengua española: "En la mayoría de los textos prevalece el sentido explícito y el valor de la palabra culmina en su sentido literal, porque la primera percepción del autor es comunicar, transmitir un mensaje en ausencia de estrategias formales o pretensiones estéticas" (El Gamoun, 2204: 158). En el autor analizado, la escritura en lengua española resulta de una elección personal con el fin de compartir con el lectorado hispanohablante las percepciones de un nativo con respecto a los cambios sociales de su país en la segunda mitad del siglo XX. Los universos recreados en las ficciones de Rekab aparecen impregnados de una dimensión intercultural inherente a la sociedad marroquí, que como ya hemos señalado con anterioridad, son 
el resultado de su posición geográfica y de su pasado histórico de relaciones culturales con vecinos e invasores. Su acto creativo adquiere, pues, una dimensión liberadora y expansiva que, según El Gamoun, otorga además un carácter internacional "sin dejar de ser nacional" a esta literatura emergente a la que pertenece (El Gamoun, 2004: 158).

Y tal y como afirmaba E. Santos, “En adoptant l'espagnol comme langue d'expression, ces écrivains marocains ont recours à un instrument légitime qu'ils revendiquent et dans lequel ils insufflent la voix profonde, polyédrique et contradictoire de leur culture" (Santos, 2006a). En los cuentos y novelas analizadas, la imbricación musical entre el español y el árabe genera una textura que se manifiesta en las imágenes de la cultura marroquí que ilustran y embellecen la creación literaria de Mohamed Bouissef Rekab (Gahete et al., 2008: 31).

Reflexionar sobre el alcance de escritores como el caso que nos ha ocupado y sobre su contribución a la consolidación de una tradición literaria en español en Marruecos, nos brinda la oportunidad no sólo de otorgarles un reconocimiento, sino también la posibilidad de acercarse de manera particular a Marruecos desde la perspectiva de los propios marroquíes. Hemos querido cerrar nuestro estudio citando al propio M. Bouissef Rekab como figura de la alteridad más allá de la bipolaridad franco-árabe en el Magreb mediterráneo:

Ce que nous essayons tout simplement de faire, c'est de la culture marocaine dans une langue qui nous appartient, à nous aussi. Contrairement à l'écrivain espagnol qui prétend dire quelque chose de notre culture, notre regard est intérieur, il participe totalement à la réalité qu'il affronte, il comprend, expose, invente depuis l'intérieur et se trouve pour cela moins enclin au stéréotype et à la distorsion (Santos, 2006b).

\section{Bibliografía}

BOUNOU, A. (coord.) (1998). Escritura marroquí en lengua española. Fez: InfoPrint.

CHAKOR, M. y MACIAS, S. (1996). Literatura marroquí en lengua castellana. Madrid: Prisma.

EL GAMOUN, A. (2004). "La literatura marroquí de expresión española: un imaginario en ciernes". Escritura marroquí en lengua española II. Creación y comparación (1975-2000). (Coord. A. Tazi). Fez: Post-Modernité. 
GAHETE, M., LIMAMI, A., MGARA, A. M., SARRIA, J. y TAZI, A. (2008). Calle del agua. Antología de la Literatura Hispanomagrebí. Madrid: Sial.

KATHIBI, A. (1983). Maghreb pluriel. Paris: Denoë.

LOMAS LOPEZ, E. (2011). "La literatura hispano-magrebí y el mercado editorial: esbozo histórico". Aljamía 22: 69-78.

MADARHRI ALAOUI, A. (1991). "Réflexions sur l'identité interculturelle en littérature maghrébine". Revue de la Faculté des Lettres de Rabat 19: 12-19.

MOURA, J.-M. (2009). Littératures francophones et théories postcoloniales. Paris: PUF.

REKAB, M. B. (1994). El vidente. Tetúan: Hidaya.

REKAB, M. B. (1995). Desmesura. Tetúan: Alpha Graph.

REKAB, M. B. (1996). Inquebrantables. Tetúan: Addamir.

REKAB, M. B. (1999). Intramuros. Tánger: Altopress.

REKAB, M. B. (2004). "El mundo ficticio de la trilogía: Desmesura-Inquebrantables-Intramuros". Escritura marroquí en lengua española II. Creación y comparación (1975-2000). (Coord. A. Tazi). Fez: Post-Modernité.

REKAB, M. B. (2005). "Primeros escritores marroquíes en lengua española". Centro Virtual Cervantes. La literatura marroquí de expresión española. $<$ http://www.cvc.cervantes.es/lengua/anuario/anuario_05/bouissef/p02.htm> (Acceso 20 de julio de 2012).

SANTOS, E. (2006a). "Méditerranée. Essais de création". <http://www.babelmed. net/anteprima_stampa.php ?menu $=34 \&$ cont $=1779 \&$ lingua $=$ fr $>$ (Acceso $20 \mathrm{de}$ julio de 2012).

SANTOS, E. (2006b). "Méditerranée. Un mouvement peu connu". <http://www. babelmed.net/anteprima_stampa.php $\quad ? \mathrm{menu}=34 \&$ cont $=1780 \&$ lingua $=\mathrm{fr}>$ (Acceso 20 de julio de 2012).

TAZI, A. (coord.) (2004). Escritura marroqui en lengua española II. Creación y comparación (1975-2000). Fez: Post-Modernité. 